\title{
A Comparison of Three Different Volumes of Levobupivacaine for Caudal Block in Children Undergoing Orchidopexy and Inguinal Hernia Repair
}

\author{
Vesna Marjanovic ${ }^{a} \quad$ Ivana Budic $^{a, b}$ Marija Stevic $^{c}$ Dusica Simic ${ }^{c, d}$ \\ ${ }^{a}$ Center for Anesthesia and Resuscitation, Clinical Centre Nis, and ${ }^{b}$ Department of Anesthesiology, Faculty of \\ Medicine, University of Nis, Nis, and 'Department of Anesthesia, University Children's Hospital Belgrade, and \\ dDepartment of Anesthesiology, Faculty of Medicine, University of Belgrade, Belgrade, Serbia
}

\section{Significance of the Study}

- This study showed that the caudal block using three different volumes of $0.25 \%$ levobupivacaine yielded similar quality and duration of intra- and postoperative analgesic effects. Low-volume levobupivacaine is sufficiently effective for analgesia in children undergoing orchidopexy or inguinal hernia repair.

\section{Keywords}

Levobupivacaine $\cdot$ Volume $\cdot$ Caudal block $\cdot$ Children

\begin{abstract}
Objective: The aim of this study was to compare the efficacy of 3 different volumes of $0.25 \%$ levobupivacaine caudally administered on the effect of intra- and postoperative analgesia in children undergoing orchidopexy and inguinal hernia repair. Subjects and Methods: Forty children, aged 1-7 years, American Society of Anesthesiologists (ASA) physical status I and II, were randomized into 3 different groups according to the applied volumes of $0.25 \%$ levobupivacaine: group 1 ( $n=13): 0.6 \mathrm{~mL} \cdot \mathrm{kg}^{-1}$; group $2(n=10): 0.8 \mathrm{~mL} \cdot \mathrm{kg}^{-1}$; and group $3(n=17): 1.0 \mathrm{~mL} \cdot \mathrm{kg}^{-1}$. The age, weight, duration of anesthesia, onset time of intraoperative analgesic, dos-
\end{abstract}

\begin{tabular}{ll}
\hline KARGER & (c) 2017 S. Karger AG, Basel \\
$\begin{array}{l}\text { E-Mail karger@karger.com } \\
\text { www.karger.com/mpp }\end{array}$ & $\begin{array}{l}\text { This is an Open Access article licensed under the terms of the } \\
\text { Creative Commons Attribution-NonCommercial 3.0 Un- } \\
\text { ported license (CC BY-NC) (www.karger.com/OA-license), } \\
\text { applicable to the online version of the article only. Distribu- } \\
\text { tion permitted for non-commercial purposes only. }\end{array}$
\end{tabular}

age, and addition of intraoperative fentanyl were compared among the groups. The time to first use of the analgesic and the number of patients who required analgesic $24 \mathrm{~h}$ after surgery in the time intervals within $6 \mathrm{~h}$, between 6 and $12 \mathrm{~h}$, and between 12 and $24 \mathrm{~h}$ postoperatively were evaluated among the groups. Statistical analyses were performed with a Dunnett $t$ test, ANOVA, or Kruskal-Wallis test and $\chi^{2}$ test. Logistic regression analysis was used in order to examine predictive factors on duration of postoperative analgesia. Results: Age, weight, duration of anesthesia, onset time of intraoperative analgesic, dosage, and addition of intraoperative fentanyl were similar among the groups. The time to first analgesic use did not differ among the groups, and logistic regression modelling showed that using the 3 different volumes of levobupivacaine had no predictive influence on duration of postoperative analgesia. The numbers of pa-

Vesna Marjanovic

Center for Anesthesia and Resuscitation, Clinical Centre Nis Bul. Zorana Djindjica 48

RS-18000 Nis (Serbia)

E-Mail drvesnamarjanovic@gmail.com 
tients who required analgesics within $6 \mathrm{~h}(3 / 2 / 3)$, between 6 and $12 \mathrm{~h}(3 / 1 / 3)$, and between 12 and $24 \mathrm{~h}(1 / 0 / 2)$ after surgery were similar among the groups. Conclusion: The 3 different volumes of $0.25 \%$ levobupivacaine provided the same quality of intra- and postoperative pain relief in pediatric patients undergoing orchidopexy and inguinal hernia repair.

(c) 2017 S. Karger AG, Basel

\section{Introduction}

Caudal block is one of the most commonly used pediatric regional anesthetic techniques for postoperative analgesia [1]. Caudal block is easy to perform; extensively safe if used in children, resulting in low pain scores; and when combined with general anesthesia, it reduces the requirement for volatile agents and opioids $[2,3]$. Caudal block is performed in children undergoing surgery at the lumbosacral to midthoracic dermatomal levels with anticipated moderate-to-severe perioperative and postoperative pain [4]. The extent of analgesia during epidural blockade with local anesthesia depends on the anatomic spread of solution within the epidural space, which is determined by the injected volume [5]. However, the formula for determining the correct volumes for different cases of local anesthetic (LA) is not yet known, but it has been suggested that only high volumes of $0.7-1.0$ $\mathrm{mL} \cdot \mathrm{kg}^{-1}$ might be able to achieve an analgesic effect to the level T10 vertebra or above [6]. Certain authors reduced the applied volume to $0.5 \mathrm{~mL} \cdot \mathrm{kg}^{-1} \mathrm{LA}$ in order to avoid side effects and toxicity [7].

There are several different LA agents available for the regional block [1]. Levobupivacaine, the S-enantiomer of bupivacaine, has been promoted as an alternative to more cardiotoxic racemic bupivacaine [8]. Levobupivacaine is generally a well-tolerated anesthetic and analgesic with a wide range of clinical applications [9]. Due to different data in the literature, further studies are needed to confirm optimal volume of levobupivacaine for caudal block in children. Therefore, the aim of this prospective study was to compare the efficacy of caudal block with 3 different volumes of $0.25 \%$ levobupivacaine and the effect of intra- and postoperative analgesia of levobupivacaine in children undergoing orchidopexy and inguinal hernia repair.

\section{Subjects and Methods}

The study was approved by the Institutional Ethics Committee of Clinical Centre Nis (No. 2552/12) and the study was performed according to the Declaration of Helsinki. Informed written con-
Table 1. Children's and Infants' Postoperative Pain Scale

\begin{tabular}{llll}
\hline Item & Score 0 & Score 1 & Score 2 \\
\hline Crying & None & Moaning & Screaming \\
Facial expression & Relaxed smiling & Wry mouth & Grimacing \\
Posture of the trunk & Neutral & Variable & Rear up \\
Posture of the legs & Neutral & Kicking & Tightened \\
Motor restlessness & None & Moderate & Restless \\
\hline
\end{tabular}

sent was obtained from the parents. Forty patients scheduled for orchidopexy and/or inguinal hernia repair, aged 1-7 years, American Society of Anesthesiologists (ASA) physical status I and II, were included in this prospective randomized study, which was conducted over a period of 6 months from May 2015 to October 2015. Exclusion criteria were local infection; bleeding tendency; congenital spinal anomaly; neurologic diseases; and serious renal, hepatic, lung, and cardiac diseases.

All the children fasted and were premedicated with intramuscular midazolam $0.1 \mathrm{mg} \cdot \mathrm{kg}^{-1} 30 \mathrm{~min}$ before surgery. Peripheral intravenous access with 20-22 G was secured and intravenous induction with propofol $2 \mathrm{mg} \cdot \mathrm{kg}^{-1}$ was administered. If the peripheral intravenous access was missed, sevoflurane was used for anesthesia induction. Anesthesia was maintained with a continuous intravenous propofol infusion of $6 \mathrm{mg} \cdot \mathrm{kg} \cdot \mathrm{h}^{-1}$ and the airway was controlled using a facial mask that allowed spontaneous breathing of oxygen and air. Thereafter, a caudal block was performed in the left lateral decubitus position using a 22 or $23-\mathrm{G}$, sterile, disposable hypodermic needle. Patients were computer randomized to receive levobupivacaine $0.25 \%$ (Chirocaine ${ }^{\circledR}$; Abbott, Latina, Italy) in 3 different total doses: group 1: $0.6 \mathrm{~mL} \cdot \mathrm{kg}^{-1}(n=13)$; group 2: $0.8 \mathrm{~mL} \cdot \mathrm{kg}^{-1}(n=10)$; and group $3: 1.0 \mathrm{~mL} \cdot \mathrm{kg}^{-1}(n=17)$, caudally administered. Levobupivacaine $0.25 \%$ was prepared by diluting $0.5 \%$ levobupivacaine with normal saline in the ratio of $1: 1$. If blood or CSF was not aspirated, LA was injected. The patients were positioned for surgery after a delay of at least 15-20 min between caudal blockade and surgical incision. Noninvasive blood pressure, heart rate, and pulse oximetry $\left(\mathrm{SpO}_{2}\right)$ were monitored continuously. The propofol infusion was stopped at the beginning of skin suture. After surgery, patients were transferred to the recovery room.

The primary outcome of the study was the clinical efficacy of the caudal block during operation. Caudal block efficacy was estimated by the absence of gross movements, as well as by the significant change $(>20 \%)$ in pulse rate and/or respiratory rate with the inguinal incision in those undergoing inguinal hernia repair and orchidopexy. In case of change in 2 of these 3 clinical parameters mentioned above, the block was considered clinically ineffective. In case of inadequate analgesia after incision or during operation, a supplementary intravenous bolus of fentanyl was administered.

Secondary outcome measures were the onset time of intraoperative analgesic, duration of postoperative analgesia, and using analgesic after caudal block. The onset time of caudal block was estimated by a mechanical stimulus at the surgical dermatome or at the immediate superior dermatome with a modified Allis clamp $3 \mathrm{~min}$ after LA injection [10]. Patients were stimulated every $3 \mathrm{~min}$ 
Table 2. Demographic and clinical characteristics of the investigated groups with caudal block

\begin{tabular}{lccc}
\hline Characteristics & $\begin{array}{l}\text { Group 1 } \\
\left(0.6 \mathrm{~mL} \cdot \mathrm{kg}^{-1}\right)\end{array}$ & $\begin{array}{l}\text { Group 2 } \\
\left(0.8 \mathrm{~mL} \cdot \mathrm{kg}^{-1}\right)\end{array}$ & $\begin{array}{c}\text { Group 3 } \\
\left(1.0 \mathrm{~mL} \cdot \mathrm{kg}^{-1}\right)\end{array}$ \\
\hline Age, years & $2.69 \pm 1.44$ & $3.40 \pm 2.53$ & $3.00 \pm 1.80$ \\
Weight, $\mathrm{kg}$ & $13.77 \pm 3.52$ & $17.50 \pm 6.35$ & $13.65 \pm 3.59$ \\
Duration of anesthesia, min & $52.69 \pm 42.21$ & $47.00 \pm 26.48$ & $54.71 \pm 26.54$ \\
Intraoperative analgesic onset time, min & $13.33 \pm 0.58$ & $13.67 \pm 1.23$ & $12.80 \pm 1.30$ \\
Dosage of fentanyl, $\mu \mathrm{gg} \cdot \mathrm{kg}^{-1}$ & $1.13 \pm 0.25$ & $1.67 \pm 0.29$ & $1.20 \pm 0.45$ \\
Addition of intraoperative fentanyl & $4 / 13(30.77)$ & $3 / 10(30)$ & $5 / 17(29.41)$ \\
\hline
\end{tabular}

Values are presented as $n(\%)$ or means \pm SD.

Table 3. Time to first analgesic requirement of patients that received and did not receive analgesic postoperatively

\begin{tabular}{|c|c|c|c|c|}
\hline Analgesic treatment & $\begin{array}{l}\text { Group } 1 \\
\left(0.6 \mathrm{~mL} \cdot \mathrm{kg}^{-1}\right)\end{array}$ & $\begin{array}{l}\text { Group } 2 \\
\left(0.8 \mathrm{~mL} \cdot \mathrm{kg}^{-1}\right)\end{array}$ & $\begin{array}{l}\text { Group } 3 \\
\left(1.0 \mathrm{~mL} \cdot \mathrm{kg}^{-1}\right)\end{array}$ & $p$ \\
\hline Time to first analgesic, min & $888.85 \pm 50.72$ & $1,099.00 \pm 479.74$ & $877.06 \pm 51.40$ & 0.66 \\
\hline Analgesic within $24 \mathrm{~h}$ & $7 / 13(17.5)$ & $3 / 10(7.5)$ & 8/17 (20) & 0.64 \\
\hline No analgesic within $24 \mathrm{~h}$ & $6 / 13(15)$ & $7 / 10(17.5)$ & $9 / 17(22.5)$ & 0.83 \\
\hline Analgesic within $6 \mathrm{~h}$ & $3 / 13(7.5)$ & $2 / 10(5)$ & $3 / 17(7.5)$ & 0.96 \\
\hline Analgesic between 6 and $12 \mathrm{~h}$ & $3 / 13(7.5)$ & $1 / 10(2.5)$ & $3 / 17(7.5)$ & 0.79 \\
\hline Analgesic between 12 and $24 \mathrm{~h}$ & $1 / 13(2.5)$ & $0 / 10(0)$ & $2 / 17(5)$ & 0.57 \\
\hline
\end{tabular}

Values are presented as $n(\%)$ or means \pm SD.

after the caudal block until the block proved to be effective during the maximum of $15 \mathrm{~min}$ after caudal injection ( 5 stimuli). Any related movement or significant change in the heart rate or respiratory rate led to the discontinuation of the stimulus. A physiological response or movement at $15 \mathrm{~min}$ was analyzed as prolonged LA onset. Data from patients who responded with movements or physiological changes to the fifth stimulus but did not respond to the first surgical stimulus were assigned an onset time equivalent to the time between caudal block and surgical incision. The duration of postoperative analgesia was the time from caudal injection to the time of first analgesic requirement. The postoperative pain relief was evaluated using the Children's and Infants' Postoperative Pain Scale (CHIPPS) at 6, 12, and $24 \mathrm{~h}$ during recovery from anesthesia (Table 1). A total score of $\geq 4$ identified the need for supplemental analgesia [11]. In the case of a CHIPPS score of 4 or more, paracetamol $15 \mathrm{mg} \cdot \mathrm{kg}^{-1}$ was administered rectally. Postoperative assessments were made by nursing staff unaware of group allocation for at least $24 \mathrm{~h}$.

Demographic data (age, weight, duration of anesthesia); onset time of caudal block; dosage of fentanyl; addition of intraoperative fentanyl; time to first analgesic requirement; number of patients who required and did not require an analgesic in postoperative period; and using an analgesic within $6 \mathrm{~h}$, between 6 and $12 \mathrm{~h}$, and between 12 and $24 \mathrm{~h}$ in the postoperative period was evaluated.

Different Volumes of Levobupivacaine for Caudal Block in Children

\section{Statistical Analysis}

R Statistics Software Version 3.1.3. (R Foundation for Statistical Computing, Vienna, Austria) was used for the statistical analysis. The data are presented as the mean \pm SD. For comparison of patient characteristics and differences between the groups, an ANOVA or Kruskal-Wallis test was used as appropriate. Testing for normal distribution of the data was performed by a Dunnett $t$ test. A $\chi^{2}$ test was used to compare nonparametric data. Multivariate logistic regression modelling was used for determining the variables that could predict duration of postoperative analgesia. A value of $p<0.05$ was considered significant.

\section{Results}

The caudal block performed in 40 children who underwent orchidopexy and inguinal hernia repair was successful in all patients. Comparison of age, weight, duration of anesthesia, intraoperative analgesic onset time, dosage of fentanyl, and addition of intraoperative fentanyl between the investigated groups are shown in 
Table 4. Model regression and predictors such as: age, weight, duration of anesthesia, and volumes of levobupivacaine (0.6, 0.8 and $1 \mathrm{~mL} \cdot \mathrm{kg}^{-1}$ ) in predicting the time to first analgesic therapy

\begin{tabular}{|c|c|c|c|c|c|c|c|c|}
\hline & $R$ & $R^{2}$ & Adjusted $R^{2}$ & $\begin{array}{l}\text { SE of the } \\
\text { estimate }\end{array}$ & $F$ & $p$ & & \\
\hline \multirow[t]{3}{*}{ Model 2} & 0.39 & 0.15 & 0.08 & 475.68 & 2.19 & 0.11 & & \\
\hline & & \multirow{2}{*}{$\begin{array}{l}\text { Unstandardized } \\
\text { coefficient B }\end{array}$} & \multirow[t]{2}{*}{ SE } & \multirow{2}{*}{$\begin{array}{l}\text { Standardized } \\
\text { coefficient } \beta\end{array}$} & \multirow[t]{2}{*}{$t$} & \multirow[t]{2}{*}{$p$} & \multicolumn{2}{|c|}{$95 \%$ CI for B } \\
\hline & & & & & & & lower & upper \\
\hline \multirow[t]{4}{*}{ Model 2} & (Constant) & $1,293.48$ & 317.43 & & 4.08 & 0.00 & 649.70 & $1,937.26$ \\
\hline & Levobupivacaine groups & 194.64 & 102.82 & 0.32 & 1.89 & 0.07 & -13.90 & 403.17 \\
\hline & Weight & -86.36 & 37.28 & 0.80 & -2.32 & 0.03 & -161.96 & -10.76 \\
\hline & Age & 178.33 & 86.38 & 0.68 & 2.06 & 0.05 & 3.14 & 353.52 \\
\hline
\end{tabular}

Table 2. There were no significant differences between the groups regarding age (ANOVA, Kruskal-Wallis test: $p=0.58$ ), weight (Dunnett $t$ test: $p=0.07)$, sex ( $\chi^{2}$ analysis: $p=0.52$ ), and duration of anesthesia (ANOVA, Kruskal-Wallis test: $p=0.61)$. The mean analgesic onset time was $13.33 \pm 0.58 \mathrm{~min}$ in group $1,13.67 \pm 1.23 \mathrm{~min}$ in group 2 , and $12.8 \pm 1.30 \mathrm{~min}$ in group 3 , without a significant difference between the groups (Dunnett $t$ test: $p=0.63$ ). The additional dose of fentanyl was in the range of $1.13-1.67 \mu \mathrm{g} \cdot \mathrm{kg}^{-1}$ in all the groups, and there was no significant difference in the required dose of fentanyl among the investigated groups ( $\chi^{2}$ analysis: $p=$ 0.11 ). Of the 40 patients, fentanyl was added intraoperatively in $12(30 \%): 4(30.77 \%)$ in group 1, $3(30 \%)$ in group 2, and $5(29.41 \%)$ in group 3, without significant differences $(p=0.99)$.

The time to the first postoperative analgesic administration; patients who did or did not require analgesic supplementation in the postoperative period; and the use of first analgesic administration in patients within $6 \mathrm{~h}$, between 6 and $12 \mathrm{~h}$, and between 12 and $24 \mathrm{~h}$ in the postoperative period are given in Table 3. The mean postoperative duration of caudal block was $936.38 \pm 496.91 \mathrm{~min}$ in all 40 patients and there was no statistical difference among the groups: $888.85 \pm 505.72 \mathrm{~min}$ for group 1, $1,099 \pm 479.74 \mathrm{~min}$ for group 2 , and $877.06 \pm 508.40 \mathrm{~min}$ for group 3 (ANOVA, Kruskal-Wallis test: $p=0.66$ ). The shortest duration of postoperative analgesia was 300 min. In addition, no statistical difference was found among the 3 groups regarding postoperative analgesic administration (ANOVA, Kruskal-Wallis test: $p=0.64$ ) (Table 3$)$. Of the 40 patients, 8 (20\%) patients required analgesics within $6 \mathrm{~h}, 7(17.5 \%)$ patients required analge- sics between 6 and $12 \mathrm{~h}$, and $3(7.5 \%)$ patients required analgesics between 12 and $24 \mathrm{~h}$. There was no statistical difference between the 3 groups in terms of receiving analgesic within $6 \mathrm{~h}$ ( $\chi^{2}$ analysis: $p=0.96$ ), between 6 and $12 \mathrm{~h}$ ( $\chi^{2}$ analysis: $\left.p=0.79\right)$, and between 12 and $24 \mathrm{~h}\left(\chi^{2}\right.$ analysis: $p=0.57$ ) (Table 3). Of the 40 patients, 22 (55\%) did not require any analgesic in the postoperative period. Model regression analysis showed that variables such as age, weight, duration of anesthesia, and volumes of levobupivacaine $\left(0.6,0.8\right.$, and $\left.1 \mathrm{~mL} \cdot \mathrm{kg}^{-1}\right)$ did not have any impact on the duration of postoperative analgesia (time to first analgesic; $\mathrm{F}=2.186, p=0.107$ ) (Table 4).

\section{Discussion}

In this study, 3 different volumes $(0.6,0.8$, and 1 $\left.\mathrm{mL} \cdot \mathrm{kg}^{-1}\right)$ of $0.25 \%$ levobupivacaine for caudal block provided similar quality and duration of intraoperative and postoperative pain relief in the pediatric patients undergoing orchidopexy and inguinal hernia repair. The 3 most important variables that determined the quality and level of caudal block were dose, volume, and concentration of the solution used as previously reported $[1,12]$. Increasing the injected volume of LA between 0.5 and 1.0 resulted in a modest increase of the caudal spread of the injected solution. However, in practice, $1 \mathrm{~mL} \cdot \mathrm{kg}^{-1}$ is a generally suitable volume of LA for pediatric surgeries below T10-level analgesia [13-15]. The finding that 3 different volumes of $0.25 \%$ levobupivacaine, 3 different doses of $\mathrm{LA}, 1.5,2.0$ and $2.5 \mathrm{mg} \cdot \mathrm{kg}^{-1}$, provided similar analgesic effects could indicate that lower volumes provided equal analgesic effects as well as higher volumes of levobupiva- 
caine. Analgesic effects of lower doses of LA obtained within the first group of patients were similar to those reported by Yao et al. [16] who used the same clinical dose of levobupivacaine $\left(1.5 \mathrm{mg} \cdot \mathrm{kg}^{-1}\right)$ as an optimal clinical dose for inguinal hernia repair. However, other studies [1, 17] indicated that caudal blocks with high volume/low concentration of LA, or vice versa, were more effective in blocking spermatic cord traction response during orchidopexy, but the investigated dose in both cases $(2 \mathrm{mg}$ $\mathrm{kg}^{-1}$ ) was higher than the dose administered in our first group $\left(1.5 \mathrm{mg} \cdot \mathrm{kg}^{-1}\right)$. Because pediatric patients were involved in this study, the doses of LA used were reduced and thereby toxicity of LA was avoided similar to other studies $[7,18-20]$ that did not report adverse events of LA when the recommended dose of $2.5 \mathrm{mg} \cdot \mathrm{kg}^{-1}$ was used. However, adequate care should be taken regarding pediatric patients as recommended previously [21,22].

The intraoperative analgesic onset time was 12.8$13.67 \mathrm{~min}$ in our study, which was consistent with 11.4 min found in the study of Breschan et al. [23]. Between the groups of patients, the duration of postoperative analgesia was similar regardless of the volumes of levobupivacaine used, $0.6-1 \mathrm{~mL} \cdot \mathrm{kg}^{-1}$, which is similar to the study of Schrock and Jones [24] who used volumes of 0.7-1.3 $\mathrm{mL} \cdot \mathrm{kg}^{-1}(0.175 \%$ of bupivacaine $)$, which resulted in a similar duration of postoperative analgesia. However, the duration of postoperative analgesia could not be compared because of different clinical doses used. This finding was confirmed by the logistic regression model, which showed that the 3 different volumes of levobupivacaine had no significant influence on the duration of postoperative analgesia. In our study, $45 \%$ of the patients required rescue analgesia postoperatively, while in the studies of Laiq et al. [25], Girwalkar-Bagle et al. [26], and Breschan et al. [23], the percentages of patients requiring postoperative rescue analgesia within $24 \mathrm{~h}$ were 30,52 , and $60 \%$, respectively. It should be noted that designs of their studies were different from our study.

\section{Conclusion}

In this study, the 3 different volumes of $0.25 \%$ levobupivacaine used for single-shot caudal anesthesia in children who underwent orchidopexy and inguinal hernia repair provided effective, adequate, and similar analgesic effects in the intraoperative and postoperative period.

\section{Disclosure Statement}

The authors report no conflicts of interest.

\section{References}

1 Silvani P, Camporesi A, Agostino MR, et al: Caudal anesthesia in pediatrics: an update. Minerva Anestesiol 2006;72:453-459.

2 Giaufre E, Dalens B, Gombert A: Epidemiology and morbidity of regional anesthesia in children: a one-year prospective survey of the French language society of pediatric anesthesiologists. Anesth Analg 1996;83:904-912.

3 Tobias JD: Postoperative analgesia and intraoperative inhalational anesthetic requirements during umblical herniorrhaphy in children: postinsicional local infiltration versus preinsicional caudal block. J Clin Anesth 1996;8:634-638.

4 Tsui BC, Tarkkila P, Gupta S, et al: Confirmation of caudal needle placement using nerve stimulation. Anesthesiology 1999;91:374378.

5 Hong JY, Han SW, Kim WO, et al: A comparison of high volume/low concentration and low volume/high concentration ropivacaine in caudal analgesia for pediatric orchiopexy. Anesth Analg 2009;109:1073-1078.
6 Thomas M, Howard R, Yule C, et al: The effect of volume of local anaesthetic on the anatomical spread of caudal block in children age 1-7 years. Paediatr Anaesth 2010;20:1017-1021.

7 Locatelli B, Ingelmo P, Sonzogni V, et al: Randomized, double-blind, phase III, controlled trial comparing levobupivacaine $0.25 \%$, ropivacaine $0.25 \%$ and bupivacaine $0.25 \%$ by the caudal route in children. Br J Anaesth 2005; 94:366-371.

8 Stewart J, Kellett N, Castro D: The central nervous system and cardiovascular effects of levobupivacaine and ropivacaine in healthy volunteers. Anesth Analg 2003;97:412-416.

9 Sanford M, Keating GM: Levobupivacaine: a review of its use in regional anaesthesia and pain management. Drugs 2010;70:761-791.

10 Antognini JF, Carstens E: A simple, quantifiable and accurate method for applying a noxious mechanical stimulus. Anesth Analg 1998;87:1446-1449.
11 Büttner W, Finke W: Analysis of behavioral and physiological parameters for the assessment of postoperative analgesic demand in newborns, infants and young children: a comprehensive report on seven consecutive studies. Paediatr Anaesth 2000;10:303-318.

12 Wolf AR, Valley RD, Fear DW, et al: Bupivacaine for caudal analgesia in infants and children: the optimal effective concentration. Anesthesiology 1988;69:102-106.

13 Armitage EN: Regional anaesthesia in paediatrics. Clin Anaesthesiol 1985;3:553-568.

14 Busoni P, Andreucetti T: The spread of caudal analgesia in children: a mathematical model. Anaesth Intensive Care 1986;14:140-144.

15 Frawley GP, Downie S, Huang GH: Levobupivacaine caudal anesthesia in children: a randomized double-blind comparison with bupivacaine. Paediatr Anaesth 2006;16:754-760.

16 Yao YS, Qian B, Chen BZ, et al: The optimum concentration of levobupivacaine for intraoperative caudal analgesia in children undergoing inguinal hernia repair at equal volumes of injectate. Anaesthesia 2009;64:23-26.
Different Volumes of Levobupivacaine for Caudal Block in Children
Med Princ Pract 2017;26:331-336

DOI: $10.1159 / 000475936$ 
17 Verghese ST, Hannallah RS, Rice LJ, et al: Caudal anesthesia in children: effect of volume versus concentration of bupivacaine on blocking spermatic cord traction response during orchidopexy. Anesth Analg 2002;95: 1219-1223.

18 Smith RH, Sanders JC: Safe dose of levobupivacaine (Chirocaine) in caudal analgesia in children. Br J Anaesth 2003;90:400-401.

19 Taylor R, Eyres R, Chalkiadis GA, et al: Efficacy and safety of caudal injection of levobupivacaine, $0.25 \%$, in children under 2 years of age undergoing inguinal hernia repair, circumcision or orchidopexy. Paediatr Anaesth 2003; 13:114-121.
20 Astuto M, Disma N, Arena C: Levobupivacaine $0.25 \%$ compared with ropivacaine $0.25 \%$ by the caudal route in children. Eur J Anaesth 2003;20:826-830.

21 Cortı'nez LI, Fuentes R, Solari S, et al: Pharmacokinetics of levobupivacaine $(2.5 \mathrm{mg} / \mathrm{kg})$ after caudal administration in children younger than 3 years. Anesth Analg 2008;107: 1182-1184.

22 Lonnqvist P: Toxicity of local anesthetic drugs: a pediatric perspective. Pediatr Anesth 2012;22:39-43.

23 Breschan C, Jost R, Krumpholz R, et al: A prospective study comparing the analgesic efficacy of levobupivacaine, ropivacaine and bupivacaine in pediatric patients undergoing caudal blockade. Paediatr Anesth 2005;15: 301-306.
24 Schrock CR, Jones MB: The dose of caudal epidural analgesia and duration of postoperative analgesia. Paediatr Anaesth 2003;13:403408.

25 Laiq N, Khan MN, Tahmeedullah, et al: Comparison of caudal bupivacaine and bupivacaine tramadol for postoperative analgesia in children undergoing hypospadias surgery. J Coll Physicians Surg Pak 2009;19:678-681.

26 Girwalkar-Bagle A, Thatte W, Choudhari S: Preemptive caudal anaesthesia in children with bupivacaine-tramadol and levobupivacaine-tramadol: a randomized, double-blind, prospective study. Anaesth Pain Intensive Care 2015;19:13-19. 